\title{
Cesarean vs Vaginal Delivery : An Institutional Experience
}

\author{
Shanta Sharma, ${ }^{1}$ Indra Dhakal ${ }^{2}$ \\ 'Department of Community Medicine, Devdaha Medical College and Research Institute, Rupandehi, Nepal, ${ }^{2}$ Department of
} Orthopaedics, Lumbini Zonal Hospital, Bułwal, Rupandehi, Nepal.

\section{ABSTRACT}

Introduction: According to the $\mathrm{WHO}, 15 \%$ of deliveries have precise indication for cesarean section where it is mandatory for the preservation of maternal and/or fetal health. Increasing rates of Lower Segment Caesarean Sections puts foreword various question that, whether a LSCS need to be reflected as a normal delivery in this twenty first century. There are conflicting reports regarding the safety of caesarean sections. While a significant number of cesarean delivery are performed for obstetrical indications, some are simply due to maternal request and may incur several risks for the child. Not much study has compared the complications of caesarean section with those of vaginal birth. Objective of this study is to find out and compare the common complications of cesarean section with vaginal deliveries on mothers.

Methods: A descriptive study was conducted in two selected hospitals of Rupandehi district, Nepal. Data was collected as per pretested structured proforma from 550 respondents randomly and analyzed by using SPSS, MANOVA and Chi-square test to determine associations between categorical variables.

Results: In total of 550 mothers, 408 (74.2\%) had vaginal delivery and $142(25.8 \%)$ had cesarean delivery.The common maternal complications were postpartum hemorrhage 116 (21.1\%), prolonged labor 47 (8.5\%) and wound infection 42 (7.6\%).

Conclusions: The result of the study shows that the maternal complications were higher among LSCS compared to vaginal delivery.

Keywords: LSCS; maternal complications; parity; vaginal delivery.

\section{INTRODUCTION}

Increasing rates of Caesarean Sections puts foreword various question that, whether a LSCS need to be reflected as a normal delivery in this twenty first century. In the United States the rate of cesarean delivery has risen $48 \%$ since 1996 , reaching a level of $31.8 \%$ in $2007 .{ }^{1}$ This trend is reflected in many parts of the world, China, approaching $50 \%^{2}$ and some private clinics in Brazil approaching $80 \% .^{3}$

With the sky rocketing caesarean section rates an increasing number of women face the issue of mode of delivery in their current pregnancy. There are conflicting reports regarding the safety of caesarean sections. ${ }^{4,5}$ When LSCS is framed in such ways it is possible to understand the increasingly common claim that it is the normal delivery of the $21^{\text {st }}$ century.

Correspondence: Dr. Indra Dhakal, Department of Orthopaedics, Lumbini Zonal Hospital, Butwal, Rupandehi, Nepal. Email: drindradhakal@gmail.com, Phone: +977-9857035444. 
However, such a claim needs to be balanced by the fact that, in spite of all the progress in medicine and anesthesiology, there remains significant risk associated with caesarean sections, ${ }^{6}$ present study will aim to explore it.

\section{METHODS}

A descriptive cross sectional study was conducted in Rupandehi district, Nepal from 2016 January to 2016 July. Rupandehi District was selected purposively because Rupandehi District is one of the terai districts where most of the delivery occurs. There are 18 Hospitals in Rupandehi district where delivery services are offered. Purposively 2 hospitals were selected. They are Lumbini zonal hospital (Government) and Siddhartha children and women hospital (Private Mission Hospital). Mothers who delivered through normal delivery and Caesarean section in selected Hospitals were study unit. Data was collected as per pretested structured proforma from 550 respondents randomly till the completion of sample size. A set of structured pretested schedule was used for data collection. Data was collected through direct interview by the researcher with the help of schedule and was analyzed using SPSS, Manova and Chi square test to determine association between categorical variables.

Ethical approval was taken from Sam Higginbottom Institute of Agriculture, Technology and Sciences, institutional ethical committee for biomedical Research on Human Participants, SHIATS, Allahabad, and Nepal health research council (NHRC) Kathmandu, Nepal. Authorities of Selected Hospitals and Respondents were fully informed about objectives of study and verbal consent was taken before data collection.

\section{RESULTS}

This study reveals that majority of respondents were from 20 to 30 years of age $366(66.7 \%)$. Majority of respondents had vaginal mode of delivery 408 (74.20\%), followed by LSCS 142 (25.8\%). The common maternal complications were postpartum hemorrhage $116(21.1 \%)$, prolonged labor 47 (8.5\%), wound infection 42 (7.6\%), vaginal tear $35(6.40 \%)$, mal presentation $11(2 \%)$,surgical injury $3(0.50 \%)$ and maternal death $3(0.50 \%)$.

Total 142 (25.8\%) of respondent have LSCS, among which majority were elective $102(18.5 \%)$ followed by emergency LSCS 40 (7.3\%) (Table 1).
Table 1. Mode of delivery of the respondent.

\begin{tabular}{lll}
\hline $\begin{array}{l}\text { Mode of delivery } \\
\text { Spontaneous vaginal } \\
\text { delivery }\end{array}$ & $\mathbf{n}(\%)$ \\
$\begin{array}{l}\text { Vaginal delivery with } \\
\text { episiotomy }\end{array}$ & $170 \quad(30.90)$ \\
$\begin{array}{l}\text { Instrumental delivery } \\
\text { Emergency LSCS }\end{array}$ & $51 \quad(09.30)$ \\
Elective LSCS & $40 \quad(07.30)$ \\
Total & 102 & $(18.50)$ \\
\hline
\end{tabular}

$72(21.1 \%)$ respondent have postpartum hemorrhage, there is no association between PPH and mode of delivery (Table 2).

\begin{tabular}{|c|c|c|c|}
\hline $\begin{array}{l}\text { Mode of } \\
\text { delivery }\end{array}$ & $\begin{array}{l}\text { Normal } \\
\mathrm{n}(\%)\end{array}$ & $\begin{array}{l}\mathrm{PPH} \\
\mathrm{n}(\%)\end{array}$ & $\begin{array}{l}\text { Total } \\
\mathrm{n}(\%)\end{array}$ \\
\hline Vaginal & $344(58.4)$ & $64(15.8)$ & $408(74.2)$ \\
\hline LSCS & $134(20.5)$ & $8(5.3)$ & $142(25.8)$ \\
\hline Total & 478 (78.9) & $72(21.1)$ & $550(100.0)$ \\
\hline
\end{tabular}

$(\chi 2=0.051$, level of significance $=0.05 \% d f=1 P>0.05$, Not significant.)

$36(8.5 \%)$ of respondent have prolong labour, prolonged labour was significantly higher among vaginal delivery (Table 3).

\begin{tabular}{l}
$\begin{array}{l}\text { Table 3. Association between mode of delivery and } \\
\text { prolonged labour. }\end{array}$ \\
\begin{tabular}{llll}
\hline $\begin{array}{l}\text { Mode } \\
\text { of } \\
\text { delivery }\end{array}$ & $\begin{array}{l}\text { No } \\
\text { Complication }\end{array}$ & $\begin{array}{l}\text { Prolonged } \\
\text { labour }\end{array}$ & Total \\
Vaginal & $377(66.5)$ & $31(7.6)$ & $408(74.2)$ \\
LSCS & $137(24.9)$ & $5(0.9)$ & $142(25.8)$ \\
Total & $514(91.5)$ & $36(8.5)$ & 550 \\
$(100.0)$
\end{tabular} \\
\hline
\end{tabular}

$\left(\chi^{2}=6.18, \quad\right.$ Level of significance $=0.05 \%$ for $1 \mathrm{df}, P<0.05$ Significant.)

$42(7.6 \%)$ of respondent have wound infection, wound infection was significantly higher among cesarean delivery ( Table 4). 


\begin{tabular}{|c|c|c|c|}
\hline $\begin{array}{l}\text { Mode of } \\
\text { delivery }\end{array}$ & $\begin{array}{l}\text { No } \\
\text { Complication } \\
\mathrm{n}(\%)\end{array}$ & $\begin{array}{l}\text { Wound } \\
\text { infection } \\
n(\%)\end{array}$ & $\begin{array}{l}\text { Total } \\
\text { n (\%) }\end{array}$ \\
\hline Vaginal & 390 (70.9) & 18 (3.3) & $408(74.2)$ \\
\hline LSCS & $118(21.5)$ & $24(4.4)$ & $142(25.8)$ \\
\hline Total & $508(92.4)$ & $42(7.6)$ & $550(100.0)$ \\
\hline
\end{tabular}

$\left(\chi^{2}=6.21\right.$, Level of significance $=0.05 \%$ for $1 \mathrm{df}$ ,$P<0.05$ Significant.)

Total $3(0.5 \%)$ of respondent have surgical injury, surgical injury was significantly higher among cesarean delivery (Table 5).

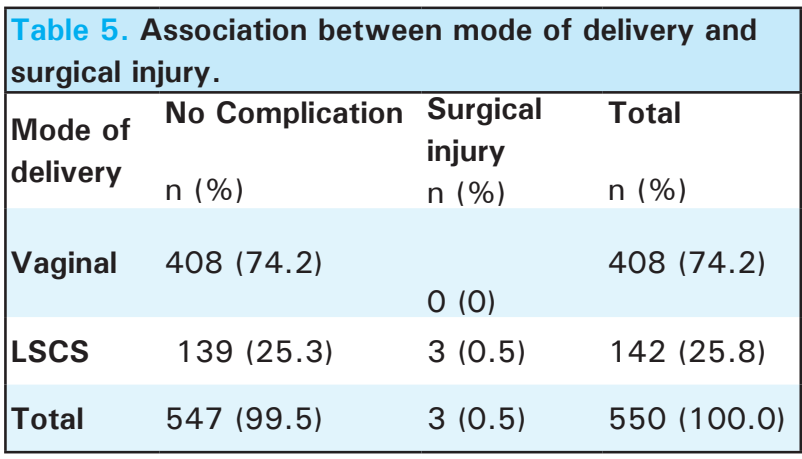

$(\chi 2=11.5, \quad$ Level of significance $=0.05 \%$ for $1 \mathrm{df}, P<0.05$ significant)

Total $3(0.5 \%)$ of respondent have maternal death, maternal death was significantly higher among cesarean delivery (Table 6).

\begin{tabular}{|llll|}
\hline \multicolumn{4}{|c|}{ Mable 6. Mode of delivery versus maternal death. } \\
\hline $\begin{array}{l}\text { Mode of } \\
\text { delivery }\end{array}$ & $\begin{array}{l}\text { Complication } \\
\mathrm{n}(\%)\end{array}$ & $\begin{array}{l}\text { Maternal } \\
\text { death }\end{array}$ & Total \\
Vaginal & $407(74.0$ & $1(0.2 \%)$ & $\mathrm{n}(\%)$ \\
LSCS & $140(25.5)$ & $2(0.4 \%)$ & $142(25.8)$ \\
Total & $547(99.5)$ & $3(0.5 \%)$ & $550(100.0)$ \\
\hline
\end{tabular}

$\left(\chi^{2}=7.88\right.$, Level of significance $=0.05 \%$ for $1 \mathrm{df}$ ,$P<0.05$ Significant.)

\section{DISCUSSION}

This study shows that 142 (25.80) percent respondents delivered by LSCS. Similar study done by Anand (2006) medical college, Ahmadabad, Gujarat, India reported that total number of deliveries during the period was 1632, out of them 411 deliveries were by cesarean section thereby making a lower segment cesarean section rate of 25.18 per cent. ${ }^{7}$ Another similar study by Kamiliya also reported that in New Zealand, one in four, and in Queensland, Australia, one in three women, is reported as delivering by caesarean section. The recent rise in LSCS rate has became a worldwide phenomenon. Lower segment caesarian segment rate in U.S.A has increased to $29.1 \%$, England $21.5 \%$, and in Latin American nations $40 \%{ }^{8}$

In this study $42.7 \%$ of respondent had complications related to delivery process. The common maternal complications were postpartum hemorrhage 116 $(21.1 \%)$, prolonged labor $47(8.5 \%)$, wound infection $42(7.6 \%)$, vaginal tear $35(6.40 \%)$, mal presentation $11(2 \%)$, surgical injury $3(0.50 \%)$ and maternal death $3(0.50 \%)$. Similarly, Nepal Monitor shows that pregnancy and delivery-related causes are amongst the top ten reasons for maternal mortality in Nepal. ${ }^{9}$

Majority of respondents had the complication of postpartum hemorrhage 116 (21.1\%). Nepal Monitor (2010) shows that postpartum hemorrhage has been dramatically reduced, down from $41 \%$ in 1998 to $24 \%$ in $2006 .{ }^{9}$ When mode of delivery and postpartum hemorrhage was correlated using chi square test, cesarean section and vaginal delivery didn't show any significant difference. Studies on the relation between actual mode of delivery and the risk of severe PPH show that caesarean delivery is associated with a higher risk of severe PPH but it is difficult to determine if planned caesarean delivery is associated with a higher risk of severe $\mathrm{PPH}$ than intended vaginal delivery. ${ }^{10}$ Similarly another study by Holm C found that planned caesarean delivery is associated with a reduced risk of severe $\mathrm{PPH}$, compared with intended vaginal delivery. ${ }^{11}$

Another major complication was prolonged labor that is 8.5 per cent which is similar to the study done by Nystedt and Hildingsson which showed that approximately $8 \%$ of all pregnant mothers did suffer from prolonged labour. ${ }^{12}$ Prolong labour and mode of delivery was correlated using chi square it was significant, that suggests prolonged labour was higher among vaginal delivery.

Study further shows that wound infection was present in 7.6 percent of respondents. There was a significant correlation between mode of delivery and wound infection and was higher among cesarean delivery. Similar study by Yokoe found that $5.5 \%$ of vaginal normal deliveries and $7.4 \%$ of abdominal deliveries were complicated with wound infection. As a whole postpartum infection rate was observed to be $6.0 \% .{ }^{13}$ Similar study by Bodner K, a total of 178 women with elective cesarean section were compared with the next parity- and age-matched women presenting in 
spontaneous labor. A significantly higher rate of wound infections ( $\mathrm{n}=16$ vs. $2, \mathrm{P}=0.0001$ ) was detected in the elective cesarean section group. ${ }^{14}$

Furthermore, $0.5 \%$ of respondent had surgical injury; surgical injury was significantly higher among cesarean delivery. Koroukian Rimm reported that compared to those with Cesarean Sections, mother with vaginal delivery are at low risk of complications. The prevalence of birth trauma is more for Cesarean Section, [AOR-0.10, $\mathrm{P}<0.001) .{ }^{15}$ While, in the United States itself, incidence of birth trauma varies from 0.02 to $3.7 \% .{ }^{16}$ Most recent study published from India showed incidence of 0.32\% during 2009-2010. In study done in Kolkata, Eastern India, predominantly from "Bengali" population, during the study period of 8 months, 73 birth injuries were noted among 4741 live births the incidence documented is $1.54 \%$ of births. ${ }^{17}$

It was also revealed that $0.5 \%$ of respondent had maternal death; maternal death was significantly higher among cesarean delivery. WHO revealed that cesarean section is associated with increased neonatal and maternal morbidity and mortality rate in India. The study found that both elective and emergency cesarean section were associated with and increased risk of maternal mortality 3.38 and $5.25 \%$ respectively. ${ }^{18}$ Similar study by Valérie Briand (2012), among the
78,166 included women, A total of $388(0.5 \%)$ women died during the labor or in the immediate post-partum period. ${ }^{19}$ Another study by Kamilya G, Twenty seven mothers died among the 13,627 cesarean delivery mothers and 19 died among 30,215 vaginal delivery mothers. Cesarean delivery was associated with a 3.01fold increase in the risk of maternal mortality, compared with vaginal delivery. ${ }^{8}$

\section{CONCLUSIONS}

Prolong labour, wound infection, surgical injury, maternal death was significantly associated with mode of delivery while postpartum hemorrhage was not associated. Prolong labour was high in vaginal delivery while wound infection, surgical injury and maternal death was high in cesarean delivery.

Cesarean delivery is increasingly perceived as a lowrisk procedure. However, the present study clearly demonstrates that there are significant increased maternal complications as compared to vaginal delivery. However the author suggests further study to be done to generalize the findings.

\section{Conflicts of Interest: None.}

\section{REFERENCES}

1. Hamilton BE, Martin JA, Ventura SJ. Births: Preliminary Data for 2007. National Vital Statistics Reports. 2009;57(12):1-21. [Full Text]

2. Rebelo F, da Rocha CM, Cortes TR, Dutra CL, Kac G. High cesarean prevalence in a national population-based study in Brazil: the role of private practice. Acta Obstet Gynecol Scand. 2010;89(7):903-8. [PubMed]

3. Lumbiganon P, Laopaiboon M, Gülmezoglu M. Method of delivery and pregnancy outcomes in Asia: the WHO global survey on maternal and perinatal health 2007-08. The Lancet. 2010;375(9713):490-9. [PubMed]

4. Curtin SC. Rates of caesarean birth and VBAC, 1991-95. Monthly vital Statistics report; Suppl3 Hyattsville (MD): National center for Health statistics; 1997: 45(11). [ [Full Text]

5. Rates of caesarean delivery - United States, 1991. MMWR Morb Mortal Wkly Rep. 1993;42(15):5-9. [PubMed]

6. Denton H. Jump in C-section births worries hospitals. New Zealand herald. 18 October 2010;262. [Full Text]

7. Anand N, Ajesh D, Kansara V, Patel S, Kagathra B, Patel R. Analysis of Trends in LSCS Rate and Indications of LSCS: A Study in a Medical College Hospital Gmers, Sola, Ahmedabad. Int J Phar Bio. 2015;2(1). [Full Text]
8. Kamilya G, Seal SL, Mukherji J, Bhattacharyya SK, Hazra A. Maternal mortality and cesarean section delivery: An analytical observational study. J Obstet Gynecol Res. 2010 April;36(2):248-253. [PubMed]

9. Nepal Monitor (2010).Cause of death for Nepali women: Study. Retrieved May 4, 2012. [Full Text]

10. Rossen J, Okland I, Nilsen OB, Eggebo TM. Is there an increase of postpartum hemorrhage, and is severe hemorrhage associated with more frequent use of obstetric interventions? Acta Obstet Gynecol Scand. 2010;89:1248-55. [PubMed]

11. Holm C, Langhoff-Roos J, Petersen KB, Norgaard A, Diness BR. Severe postpartum haemorrhage and mode of delivery: a retrospective cohort study. BJOG. 2012;119(5):596-604. [PubMed]

12. Nystedt $\mathrm{N}$ and Hildingsson H. BMC Pregnancy and ChildbirthBMC series. Biological and Medical Central Limited. 2014: 10.1186/1471-2393-14-233. [Full Text]

13. Yokoe DS, Christiansen CL, Johnson R, Sands KE, Livingston J, Shtatland ES, Platt R. Epidemiology of and surveillance for postpartum infections. Emerg Infect Dis. 2001 Sep Oct;7(5):837-41. [PubMed] 
14. Bodner K, Wierrani F, Grünberger W, Bodner-Adler B. Influence of the mode of delivery on maternal and neonatal outcomes: a comparison between elective cesarean section and planned vaginal delivery in a low-risk obstetric population. Arch Gynecol Obstet. 2011 Jun;283(6):1193-8. [PubMed]

15. Koroukian SM, Rimm AA.Comparision Caesarean Section versus Vaginal post partum: A comparative study in the academy for health services research on healthpolicies meeting in Hilliard 2000:17. [ [Full Text]

16. Sauber-Schatz EK, Markovic N, Weiss HB, Bodnar LM, Wilson JW, Pearlman MD. Descriptive epidemiology of birth trauma in the United States in 2003. Paediatr Perinat Epidemiol. 2010;24:116-24. [PubMed]
17. Warke C, Malik S, Chokhandre M, Saboo A. Birth injuries - A review of incidence, perinatal risk factors and outcome. Bombay Hosp Med J. 2012;54:202-8. [Full Text]

18. WHO, UNFPA, UNICEF, World Bank, Reduction of maternal mortality: A joint World Health Organization/ United Nations Fund for Population / United Nations Fund for Children's Education/World Bank statement. Geneva: World Health Organization; 2000. [Full Text]

19. Valérie B, Alexandre D, Michal A, Amadou S, Mamadou T, Patrick R, Laurence W, Pierre F. Maternal and Perinatal Outcomes by Mode of Delivery in Senegal and Mali: A Cross-Sectional Epidemiological Survey. PLoS One. 2012;7(10):e47352. [Full Text | DOI | PubMed] 